\title{
Glucose-Regulated Protein 78: A Novel Therapeutic Target for Amelogenin- Induced Periodontal Tissue Regeneration
}

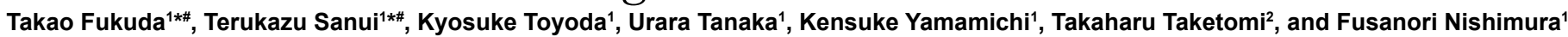

${ }^{1}$ Department of Periodontology, Division of Oral Rehabilitation, Faculty of Dental Science, Kyushu University, Fukuoka, Japan

${ }^{2}$ Dental and Oral Medical Center, Kurume University School of Medicine, Kurume, Fukuoka, Japan

"These authors contributed equally to this article

\begin{abstract}
Amelogenin, the major component of a commercial enamel matrix derivative (Straumann ${ }^{8}$ Emdogain), is commonly employed in periodontology. It is mainly used in periodontal surgery to stimulate the regeneration of periodontal tissues, including the cementum, periodontal ligament, and alveolar bone. However, the precise molecular mechanisms underlying amelogenin-induced regeneration have not yet been elucidated. Thus, to gain further insight into how amelogenin induces periodontal tissue regeneration, we performed a protein interaction screen using recombinant full-length amelogenin (rM180) as bait. Coupling affinity chromatography with proteomic analysis identified glucose-regulated protein 78 (Grp78) as a new amelogenin-binding protein. We further demonstrated that the interaction between amelogenin and Grp78 not only contributes to cell proliferation in osteoblastic cells but also enhances cell migration in periodontal ligament stem/progenitor cells. Although the potentiation effects of Grp78 should be further examined in vivo, our findings indicate the significant therapeutic potential for amelogenin-induced periodontal tissue regeneration.
\end{abstract}

Keywords: Glucose-regulated protein 78 (Grp78); Amelogenin; Extracellular matrix (ECM)

\section{Commentary}

The periodontium is mainly composed of two hard tissues and two soft tissues; the former include the alveolar bone and cementum covering the tooth root, and the latter include the periodontal ligament (PDL) tissue and gingival tissue. Periodontal disease is characterized by irretrievable damage of the tooth-supporting periodontium and is the major cause of tooth loss in adults. However, the conventional subgingival root debridement or periodontal flap surgery can only help to prevent the progression of periodontal disease and do not provide a cure. Various types of periodontal regeneration strategies have been developed to date, and application of the extracellular matrix (ECM) has been proposed as one of the most successful therapeutic strategies [1]. The ECM is well known to serve as a biological scaffold for tissue regeneration by modulating cells through the transduction of a variety of signaling pathways [2]. Furthermore, the ECM contributes to angiogenesis, recruitment of stem/progenitor cells, and remodeling of damaged tissues [3].

Enamel matrix derivative (EMD) (Straumann ${ }^{\circledR}$ Emdogain) was developed according to a concept of mimicking the tooth developmental environment [4]. EMD has been widely applied for periodontal tissue regeneration, and long-term successful clinical results have been obtained [5]. Many in vitro studies have supported the notion that EMD not only contributes to osteoconductive activity [6] but also enhances the multi-lineage differentiation of human PDL cells [7]. Amelogenins, the major $(>95 \%)$ component of EMD, belong to the ECM protein family [8]. During tooth development, ameloblasts secrete amelogenins onto the dentin root surface [9]. Consequently, amelogenin induces the formation of the PDL, thereby promoting alveolar bone formation [10]. As an ECM protein, amelogenin (Xelma, Molnlycke Health Care, and Gothenburg, Sweden) has also been used as an effective and standard treatment for hard-to-heal wounds [11]. Moreover, recent studies have demonstrated that recombinant amelogenin alone could induce in vivo periodontal tissue regeneration [12]. Although amelogenins have been suggested to serve as bioactive candidates for periodontal regeneration [4], their downstream signaling molecules have not been clearly elucidated.

To gain further insight into the molecular basis of amelogenininduced periodontal tissue regeneration, we performed an affinity chromatography-based proteomic analysis to identify amelogeninspecific binding proteins in osteoblastic cells [13]. After confirming the endocytosis of recombinant amelogenin as a precondition for physiological interaction, we found that glucose-regulated protein 78 (Grp78) was the only protein present in both the cytosolic and membrane fractions of the osteoblastic cell lysate. Grp78 is a member of the heat shock protein 70 family and is well known as an endoplasmic reticulum (ER) chaperone, which regulates the ER stress signaling pathway [14]. Recent studies have demonstrated that ER stress signaling mediates bone formation [15], and we found that the biological interaction between amelogenin and Grp78 contributed to osteoblastic cell proliferation.

PDLSCs play a central role in regenerating the periodontium, possess a self-renewal property, and differentiate into fibroblasts, osteoblasts, or cementoblasts in response to stimuli in their microenvironment [16].

*Corresponding author: Takao Fukuda, D.D.S., PhD, Assistant Professor Department of Periodontology, Division of Oral Rehabilitation, Faculty of Dental Science, Kyushu University, 3-1-1 Maidashi, Higashi-ku, Fukuoka 812-8582, Japan, Tel: +81-92-642-6358; Fax: +81-92-642-6360; E-mail: tfukuda@dent.kyushu-u.ac.jp

Terukazu Sanui, D.D.S., PhD, Lecturer, Department of Periodontology, Division of Oral Rehabilitation, Faculty of Dental Science, Kyushu University, 3-1-1 Maidashi, Higashi-ku, Fukuoka 812-8582, Japan, Tel: +81-92-642-6358; Fax: +81-92-6426360; E-mail: sanuteru@dent.kyushu-u.ac.jp

Received April 29, 2016; Accepted May 09, 2016; Published May 11, 2016

Citation: Fukuda T, Sanui T, Toyoda K, Tanaka U, Yamamichi K, et al. (2016) GlucoseRegulated Protein 78: A Novel Therapeutic Target for Amelogenin-Induced Periodontal Tissue Regeneration. Single Cell Biol 5: 137. doi:10.4172/21689431.1000137

Copyright: @ 2016 Fukuda T, et al. This is an open-access article distributed unde the terms of the Creative Commons Attribution License, which permits unrestricted use, distribution, and reproduction in any medium, provided the original author and source are credited. 
Citation: Fukuda T, Sanui T, Toyoda K, Tanaka U, Yamamichi K, et al. (2016) Glucose-Regulated Protein 78: A Novel Therapeutic Target for AmelogeninInduced Periodontal Tissue Regeneration. Single Cell Biol 5: 137. doi:10.4172/2168-9431.1000137

Page 2 of 3

As successful periodontal regeneration requires the participation of mesenchymal stem cell (MSC)-derived PDL stem cells (PDLSCs) [17], we also evaluated the interaction using the PDLSC [18]. Although Grp78 is located mainly in the ER, in stem/progenitor cells and undifferentiated tumor cells, it translocates to the cell surface, where it acts as a receptor for cell-surface signalling [19-21]. Consistent with these reports of the cell surface localization of Grp78, our confocal analysis confirmed the cell surface co-localization of amelogenin with Grp78, and showed that Grp78 specifically mediates the endocytosis of amelogenin. Considering the cell surface localization of Grp78 in PDLSCs, Grp78 appears to be an amelogenin-specific receptor in PDLSCs. We also found that the biological interaction between Grp78 and amelogenin contributes to cell migration without affecting cell proliferation. Cell migration involves cytoskeletal reorganization and induce the formation of membrane protrusions in the forms of lamellipodia and filopodia [22]. Small GTPases of the Rho family, Rac1, Cdc42, and Rho, are key molecules for cytoskeletal dynamics and control the formation of lamellipodia, filopodia, and stress fibers, respectively [23]. We further demonstrated that Rac1 activation and lamellipodia formation are critical in amelogenin-induced cell migration in PDLSCs.

In conclusion, the biological interaction of amelogenin with Grp78 shows significant therapeutic potential for amelogenin-induced periodontal tissue regeneration. The results of our in vitro studies suggest the possibility that this interaction in osteoblasts can lead to bone regeneration, and the resulting enhanced migration of PDLSCs is an essential component for the initiation of periodontal tissue regeneration. Considering that the commercial product Straumann ${ }^{\circ}$ Emdogain is derived from the porcine EMD, development of a new procedure through the combination of recombinant amelogenin and a Grp78 inducer could be a safe and reliable therapeutic strategy based on the clinical achievement of Straumann ${ }^{\oplus}$ Emdogain and the molecular basis of amelogenin. Although these effects should be further examined in vivo, our findings indicate the significant therapeutic potential for amelogenin-induced periodontal tissue regeneration (Figure 1).

\section{Contract Grant Sponsor}

Grants-in-Aid for Scientific Research C (26463137) and Research Activity Start-up (15H06492) from the Japan Society for the Promotion of Science

\section{Acknowledgments}

This work was supported by Grants-in-Aid for Scientific Research C

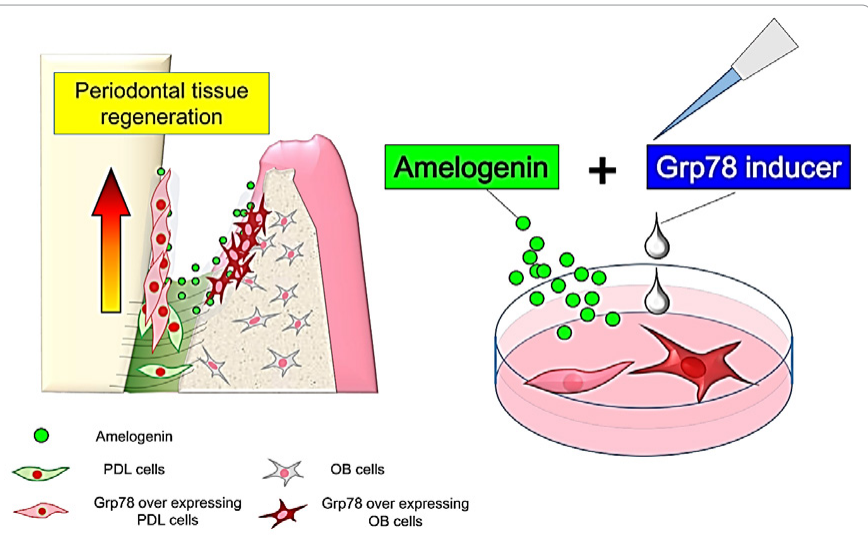

Figure 1: A schematic image for the clinical application. Therapeutic model for amelogenin-induced periodontal tissue regeneration by the combination of recombinant amelogenin and a Grp78 inducer PDL cells: Periodontal Ligament Cells, OB cells: Osteoblastic Cells.
(26463137) and Research Activity Start-up (15H06492) from the Japan Society for the Promotion of Science.

\section{Author Disclosure Statement}

The authors have declared that no conflicts of interest exist.

\section{References}

1. Saito M, Tsuji T (2012) Extracellular matrix administration as a potential therapeutic strategy for periodontal ligament regeneration. Expert Opin Biol Ther 12: 299-309.

2. Rosso F, Giordano A, Barbarisi M, Barbarisi A (2004) From cell-ECM interactions to tissue engineering. J Cell Physiol 199: 174-180.

3. Badylak SF (2002) The extracellular matrix as a scaffold for tissue reconstruction. Semin Cell Dev Biol 13: 377-383.

4. Gestrelius S, Lyngstadaas SP, Hammarström L (2000) Emdogain: periodontal regeneration based on biomimicry. Clin Oral Investig 4: 120-125.

5. Sculean A, Kiss A, Miliauskaite A, Schwarz F, Arweiler NB, et al. (2008) Tenyear results following treatment of intra-bony defects with enamel matrix proteins and guided tissue regeneration. J Clin Periodontol 35: 817-824.

6. Miron RJ, Hedbom E, Ruggiero S, Bosshardt DD, Zhang Y, et al. (2011) Premature osteoblast clustering by enamel matrix proteins induces osteoblast differentiation through up-regulation of connexin 43 and N-cadherin. PLoS One 6: e23375.

7. Amin HD, Olsen I, Knowles JC, Dard M, Donos N (2013) Effects of enamel matrix proteins on multi-lineage differentiation of periodontal ligament cells in vitro. Acta Biomater 9: 4796-4805

8. Chen E, Piddington R, Decker S, Park J, Yuan ZA, et al. (1994) Regulation of amelogenin gene expression during tooth development. Dev Dyn 199: 189198.

9. Bosshardt DD, Nanci A (2004) Hertwig's epithelial root sheath, enamel matrix proteins, and initiation of cementogenesis in porcine teeth. J Clin Periodontol 31: 184-192.

10. Tanimoto K, Huang YC, Tanne Y, Kunimatsu R, Michida M, et al. (2012) Amelogenin enhances the osteogenic differentiation of mesenchymal stem cells derived from bone marrow. Cells Tissues Organs 196: 411-419.

11. Romanelli M, Dini V, Vowden P, Agren MS (2008) Amelogenin, an extracellula matrix protein, in the treatment of venous leg ulcers and other hard-to-heal wounds: experimental and clinical evidence. Clin Interv Aging 3: 263-272.

12. Haze A, Taylor AL, Haegewald S, Leiser Y, Shay B, et al. (2009) Regeneration of bone and periodontal ligament induced by recombinant amelogenin after periodontitis. J Cell Mol Med 13: 1110-1124

13. Fukuda T, Sanui T, Toyoda K, Tanaka U, Taketomi T, et al. (2013) Identification of novel amelogenin-binding proteins by proteomics analysis. PLoS One 8 e78129.

14. Ni M, Zhang Y, Lee AS (2011) Beyond the endoplasmic reticulum: atypical GRP78 in cell viability, signalling and therapeutic targeting. Biochem $\mathrm{J} 434$ : 181-188.

15. Murakami T, Saito A, Hino S, Kondo S, Kanemoto S, et al. (2009) Signalling mediated by the endoplasmic reticulum stress transducer OASIS is involved in bone formation. Nat Cell Biol 11: 1205-1211.

16. Gould TR, Melcher AH, Brunette DM (1980) Migration and division of progenitor cell populations in periodontal ligament after wounding. J Periodontal Res 15: 20-42.

17. Seo BM, Miura M, Gronthos S, Bartold PM, Batouli S, et al. (2004) Investigation of multipotent postnatal stem cells from human periodontal ligament. Lancet 364: 149-155.

18. Toyoda K, Fukuda T, Sanui T, Tanaka U, Yamamichi K, et al. (2016) Grp78 Is Critical for Amelogenin-Induced Cell Migration in a Multipotent Clonal Human Periodontal Ligament Cell Line. J Cell Physiol 231: 414-427.

19. Eapen A, Sundivakkam P, Song Y, Ravindran S, Ramachandran A, et al. (2010) Calcium-mediated stress kinase activation by DMP1 promotes osteoblast differentiation. J Biol Chem 285: 36339-36351.

20. Zhang Y, Liu R, Ni M, Gill P, Lee AS (2010) Cell surface relocalization of the endoplasmic reticulum chaperone and unfolded protein response regulator GRP78/BiP. J Biol Chem 285: 15065-15075. 
Citation: Fukuda T, Sanui T, Toyoda K, Tanaka U, Yamamichi K, et al. (2016) Glucose-Regulated Protein 78: A Novel Therapeutic Target for AmelogeninInduced Periodontal Tissue Regeneration. Single Cell Biol 5: 137. doi:10.4172/2168-9431.1000137

Page 3 of 3

21. Spike BT, Kelber JA, Booker E, Kalathur M, Rodewald R, et al. (2014) CRIPTO/ GRP78 signaling maintains fetal and adult mammary stem cells ex vivo. Stem Cell Reports 2: 427-439.
22. Lauffenburger DA, Horwitz AF (1996) Cell migration: a physically integrated molecular process. Cell 84: 359-369.

23. Ridley AJ (2001) Rho GTPases and cell migration. J Cell Sci 114: 2713-2722. 